\title{
Proposing New Service, Data Management Concepts And Models for Improving MIS Data Processing Productivity in D\&CM System Using Javascript with GSM Mobile Service
}

\author{
St. Mai Al Qatameen \\ Jordan University, Business and Administration Department
}

Received: May 28, 2014 Accepted: June 15, 2014

doi:10.5296/ber.v4i2.6345 URL: http://dx.doi.org/10.5296/ber.v4i2.6345

\begin{abstract}
MIS has been sharing among many vital aspects in life and DCMS is no exception, by improving the methods and technologies that has been adopted in DCMS results in saving people lives, saving public and private welfare, and decreasing many losses in different life aspects and fields.

Disaster management tools for both hardware and software parts among this science are programmed and fabricated by many vendors specialists in this field so DMTs differs in level of complexity and conditions of operation, and level needed of training to keep system effective ,up and run according to the trends and areas to be deployed in.

In this paper author will propose new concepts and methods to be deployed in the MIS component that would be used in DCMS by using Ecmascript ( JavaScript ) which is one of the most important client-side script language aided by API that can be created using VB, C++, or any other platform within the GSM network via communications cloud, that is for the sake of proving the new concepts and methods in DCMS.
\end{abstract}

\section{Introduction}

Information and communication are two key factors that have an essential impact on the efficiency of disaster management Information serves as input for decision-making and includes static information, e.g. topography or building parcel data, and dynamic information e.g. position and status of damages or resources, by using new concept model for mobile data processing for deploying subsets of JavaScript and mobile application results in increasing efficiency data handling and processing thus simplifying Communication which is important for keeping the situation picture up-to-date, for collaborative decision-making and for putting decisions into practice. 


\section{MInstitute Macrothink $_{\text {Int }}$}

Business and Economic Research

ISSN 2162-4860

2014, Vol. 4, No. 2

The Management Information System (MIS) is a practical implementation of both information and communication for application in disaster management. The MIS integrates many things such as messaging system with a Geographical Information System (GIS), data-loggers , Supervisory Control and Data Acquisition( SCADA) and other resources with damage overviews.

By adding new concepts and services that could allocate the most output of data and analysis that would increase the efficiency of rescuing people and properties decreasing the losses and damages of overall country's vital resources.

\section{Proposal Review}

The development of management of the disasters and crises science among the past decade had shown adding new modeling systems, new components, and other tools in this science which in turn results in many improvements in the disasters and crises management field. By proposing new concepts, methods, new hardware and software requirements, so that new statistics model will drive the Disaster and Crisis Management System( DCM's) processes according to prior analysis and assumptions.

By proposing new techniques in data collection and data analysis model which results in improvements in disaster management components such as:

* Preparation stage.

* Response stage.

* Watch stage (this is a new proposed stage identified by writer of this paper).

According to that new demands would be created in communications industry such as additional mobile chipset level fabrication, additional data processing and manufacturing for all OEMs, service providers ,and end users.

\subsection{Disaster and Crises Management System}

According to United Nations International Strategy for Disaster Reduction (UN-ISDR, 2009) disaster is a serious disruption of the functioning of a community or a society causing widespread human ,material, economic or environmental losses which exceed the ability of the affected community or society to cope using its own resources.

Disaster can be categorized into 3 types (Shaluf, 2008), natural disasters which resulted from natural forces, man-made disasters which resulted from human decisions, and hybrid disasters which resulted from both natural and man-made causes. Natural disaster can be divided into 5 sub-groups which in turn cover 12 disaster types and more than 30 sub-types. The occurrence of natural disaster is based on the convergence of two factors, hazard and vulnerability( Guha-Sapir et al., 2004).

The UN/ISDR reports that the countries most severely affected by disasters are of low or medium income, and rank low on the scale of human development. Approximately $80 \%$ of disasters are in predominantly developing areas (Alexander, 1991, p. 212). 


\section{1l Macrothink}

Business and Economic Research

ISSN 2162-4860

2014, Vol. 4, No. 2

Mileti and his colleagues say that "losses from natural disasters occur because of development that is unsustainable" (1995, p. 122)

\subsection{New DCMS Proposed Core}

This new core suggested by the author including the following :

1) New component in DCMS model ( DAC stages new stages for which new concepts and services should be developed for ).

2) New concepts and services with the definitions. ( hardware level: new demand in mobile technology with added software level for control and analysis ).

3) Smart reactive map with pure JavaScript coding core to simplify design, boost application efficiency, and generalize concept and deployment among different level of DCMS.

\subsubsection{New components in DCMS model}

Within the components of DCMS a new component would be added prior to both response stage and directly preceding disaster stage called Watch stage, as this stage has been overlapped slyly within the pre warning stage and post disaster within a considerable duration of time. This stage assumes that there is a period of time (long or short) that response would be taken after as a cause of less information about:

* area of disaster

* victims nature and counts

* The nature and environment of disaster area

* types of damages, etc.

\subsubsection{New concepts and services}

The following keys are the concepts that would restructure and define the new design of Disaster Management Tool ( DMT )as follow:

- DCMS Shared Medical Profile (DSMP): this is the accessible medical profile database of each person (victim) who is in disaster area.

- Biometric Signature Identifier (BSI) : this is the sensor that should be fabricated, embedded into GSM mobiles unit held by the persons(victims) who are in the disaster area to identify them.

- Active for Radio Frequency Identifier (RFID) : this is the unit that should be fabricated and embedded in the GSM mobile unit as a victim locator that should work by small power source apart from mobile power source (battery) and would keep transmitting a distinct frequency rather than the Global System For Mobiling (GSM) frequency of mobile so that helping in finding buried people under the tumbles.

- New service demand to be applied into Transceiving Cell Station (especially those supplied by Eco disasters impacts data-loggers) to identify the live ( online ) and deadline GSM mobiles and their location within the area of Global System For 


\section{MInstitute Macrothink $_{\text {Int }}$}

Business and Economic Research

ISSN 2162-4860

2014, Vol. 4, No. 2

Mobiling( GSM) cell or/and with added service using triangulation processes-plus added GPS if available- in the area of disaster that will allocate the DSMP for those persons in the disaster area by identifying their identity using the BSI by which new service offered by analytical software deployed on the remote servers of the rescue and monitoring room to find the most prior crowded area of victims and injuries.

According to this sequence of rescue operation based on prioritization will allocate the area and define the needed medical and rescue tools accompanying rescue team.

\subsubsection{Platform for Deploying Proposed Core}

JavaScript as client side scripting language with expansion of using APIs among different providers facilitate and expand the use of power of this language and make it very easy to program, deploy, and maintain to meet different levels of

applications and needs by combining with other Object Oriented Language (OOP) languages such as Java, Python, PHP, C++, etc. shown many vivid applications in many fields especially in IT and Management Information System( MIS) processes and Disaster and Crisis Management System (DCMS) with Disaster Management Tool (DMT) are no exception. Using JavaScript combining with other free Object Oriented Language( OOP) such as python or C++ give more liberty to form the right management and analysis tool so giving more options , easiness of development and easiness in follow up and maintaining with one extra features such as cheapness and cross-platform to be deployed over wide different systems.

\section{Theory}

By assuming the earthquake disaster scenario to apply our new model through. A database would be used in this scenario for the sake of data collection, analysis and processing based on the following models.

1) Communication and geometry model.

2) Data processing model.

Deployment of these model and its relevant application will depend on assuming the following situations are applicable.

1) Access to Global System For Mobiling (GSM) communication towers database.

2) Access to Global System For Mobiling( GSM) radiation pattern and assisted mobile location service.

3) Access to medical profile for each person in the country with its relevant databank of thumb biometric signature.

4) Centralized backend database and application server to deploy the model scenario.

\subsection{System Work Flow Model}

Figure 1 and figure 2 represent the overall system work flow model which is implemented and developed in 2-tier models, 4 major blocks for Radio Frequency Identifier (RFID) and 


\section{Macrothink}

Business and Economic Research

ISSN $2162-4860$

2014, Vol. 4, No. 2

Biometric Signature Identifier (BSI) concept for new demand of hardware and service as shown in figure 2 and 7 major blocks for shared medical profile (DSMP) utilization concept and service as shown below in figure 3. As shown in these workflow models new procedures and processes would be added with additional hardware and software requirements to restructure the new DCMS model. However the level of details and complexities will be different among different disasters and crises levels thus different scenarios of implementation would occur.

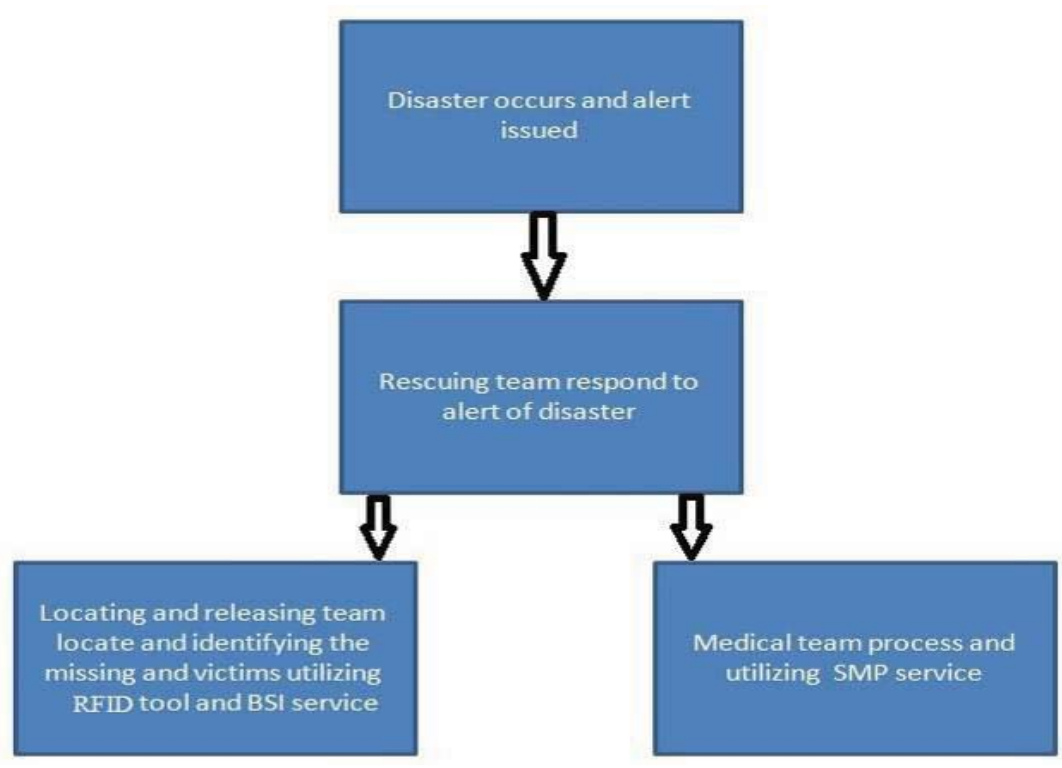

Fig.1 Integrating RFID With BSI Concept For Rescue Service 


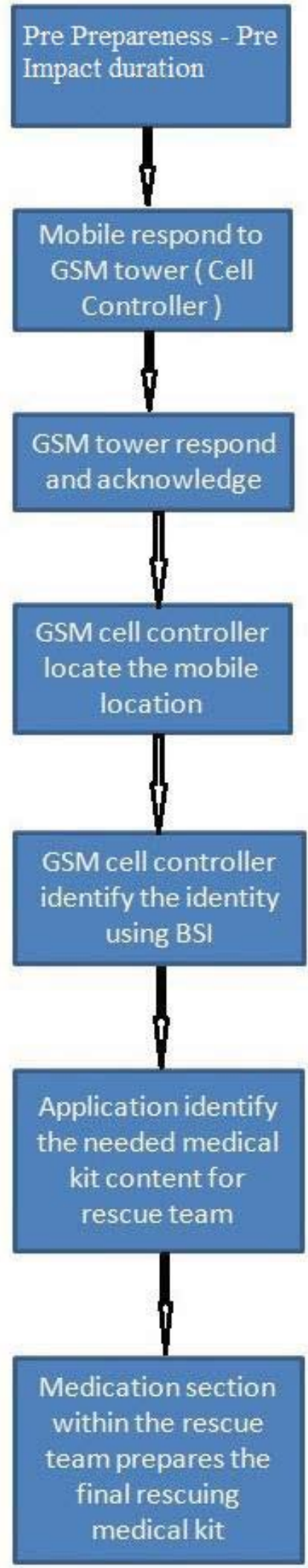

Fig.2 (DSMP) Utilization Concept And Service 


\section{MInstitute Macrothink}

\subsection{Communication Geometry vs. Watch Stages}

The Watch stage depending on the type of disaster with other issues could be extended from short period to a long one, especially when there is no much information about the degree of disaster and level of severe conditions.

Based on that if data availability with efficient analysis tool applied then this could lead to shorten the watch stages and get more desirable results in Disaster and Crisis Management (DCM). Utilizing the GSM infrastructure as major sustaining tool to enhance the quality of Disaster and Crisis Management System (DCMS). However GSM communication providers normally build their network on a planned scientific arrangement that would give the best coverage and quality of service.

\subsubsection{Disaster Coverage Analyzing Radiation Pattern}

The purpose of deploying the smart dynamic mapping system to show and allocate the whole resources for the head of Disaster and Crisis Management (DCM) and decision makers to facilitate their job and tasks. By deploying of triangulation process and/or any such assisted ground positioning system, the destined region data should be identified and locate the monitored area boundaries as chunks to facilitate the monitoring and rescuing process.

For this purpose mathematical calculations and assumptions would be identified as follow:

- Locate the GSM probable coverage boundaries to be monitored.

- Assign the maximum $\mathrm{X}-\mathrm{Y}$ and minimum $\mathrm{X}-\mathrm{Y}$ in plane to show full

- area within the computer screen as a dynamic (movable) map for monitored areas. Figure 4 shows the GSM broadcast cells with different pattern of reception and transmission assuming the linear model in two variable $\mathrm{X}-\mathrm{Y}$ plane to ease calculations.

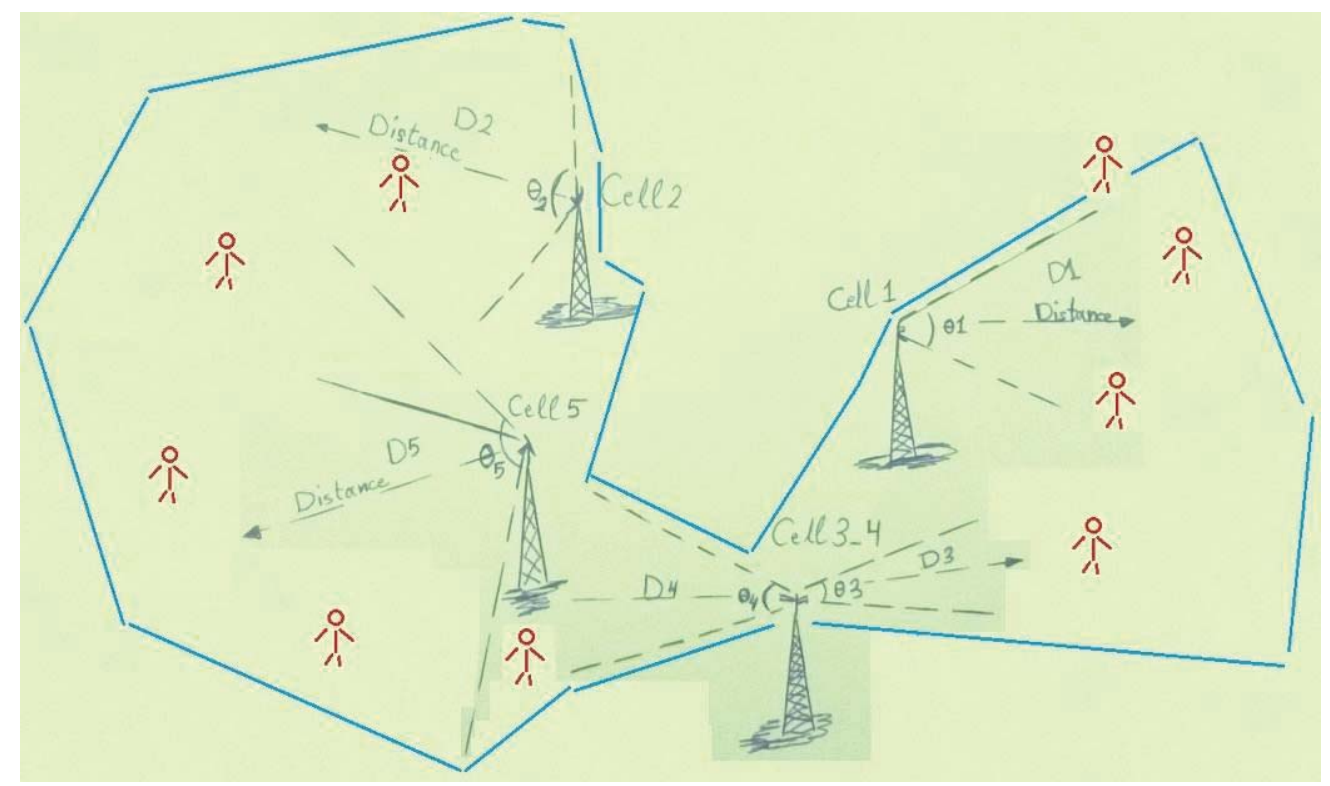

Fig.3 GSM Broadcast Pattern Area Calculation Geometry 


\section{Ml Macrothink}

Business and Economic Research

ISSN 2162-4860 2014, Vol. 4, No. 2

To define GSM boundaries for earthquake coverage scenario, the distance of coverage for each GSM cell should be calculated by identifying the angle of radiation pattern for each GSM cell. For simplifying purpose the triangle pattern of communication considered with the maximum distance Dx rather than semi oval shape as shown in figure 5.

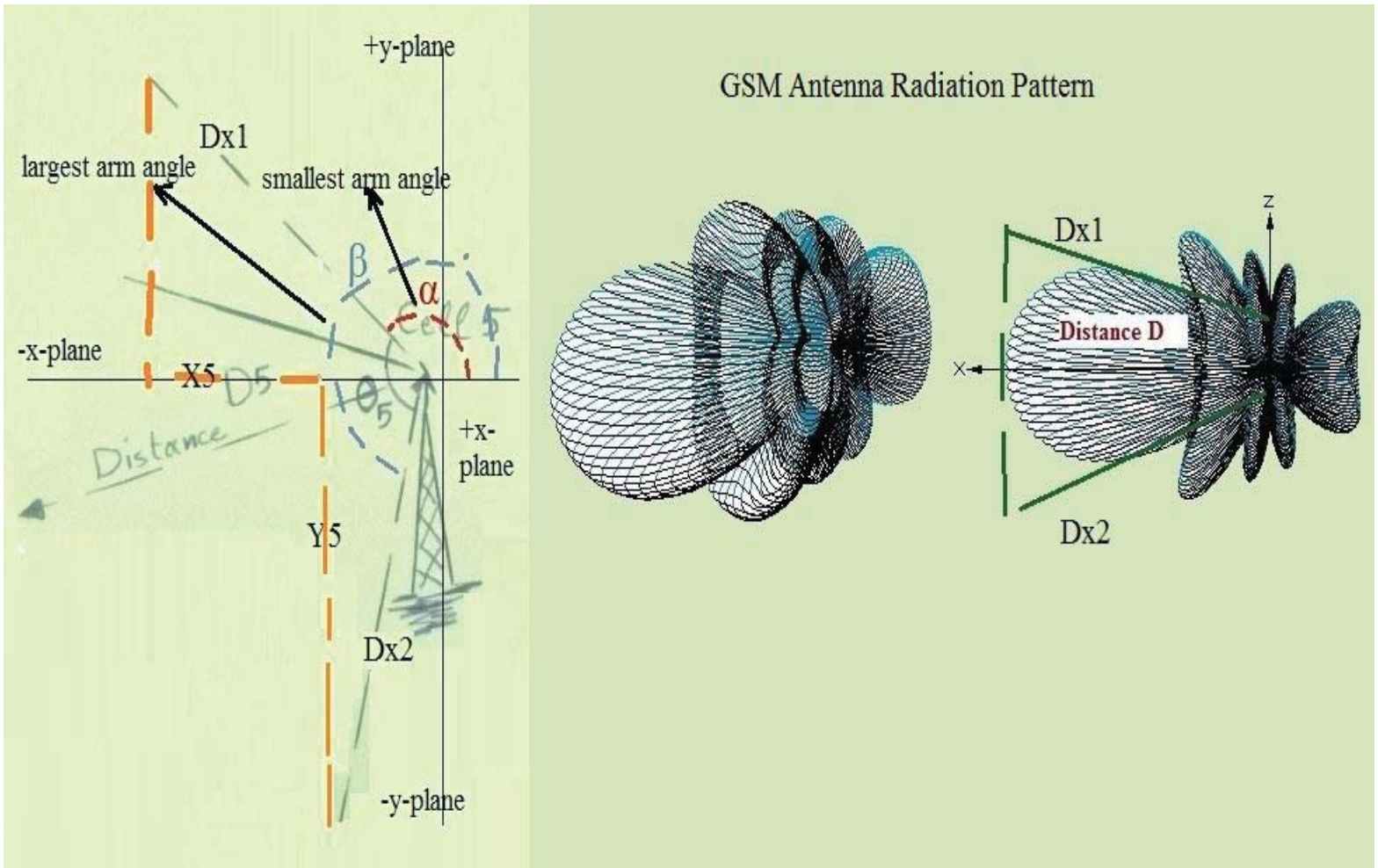

Fig.4 X-Y Calculation Simplification Using Trigonometric Model

Using Pythagorean theorem the equations become as follow:

* Angular direction from ( $+\mathrm{X}$ axis to $-\mathrm{X}$ East-North-West $)$ and from

( $-\mathrm{X}$ axis to $-\mathrm{X}$ axis West-South-East )

* Using degree in Trigonometry assuming Dx1 = Dx2

$*$ If $0^{\circ} \leq \alpha$ and $\beta \leq 180^{\circ}$ and if $\left(180^{\circ}-\alpha\right) \leq\left(180^{\circ}-\beta\right)$ then using the

following equation:

$* \mathrm{Xx}=\mathrm{Dx} 1 * \cos (\alpha)$

$* \mathrm{Yx}=\mathrm{Dx} 2 * \cos (\beta)$

* X5 $=\mathrm{D} 5 * \cos (\alpha)$

$* \mathrm{Y} 5=\mathrm{D} 5 * \cos (\beta)$

$*$ If $180^{\circ}<\beta$ and $\alpha \leq 360^{\circ}$ and if $\left(360^{\circ}-\beta\right) \leq\left(360^{\circ}-\alpha\right)$ then using the following equation: 


\section{MInstitute Macrothink}

$* \mathrm{Xx}=\mathrm{Dx} 1 * \cos (\beta)$

$* \mathrm{Yx}=\mathrm{Dx} 2 * \cos (\alpha)$

$* \mathrm{X} 5=\mathrm{D} 5 * \cos (\beta)$

$* \mathrm{Y} 5=\mathrm{D} 5 * \cos (\alpha)$

The above JavaScript code specifies boundary for each GSM cell extracted then aggregating the final result as Square view containing the whole coverage area as shown in blue lines in figure 4 . While finding the centre of whole area of coverage

(Monitor centralized) in the web browser as shown in figure 6.

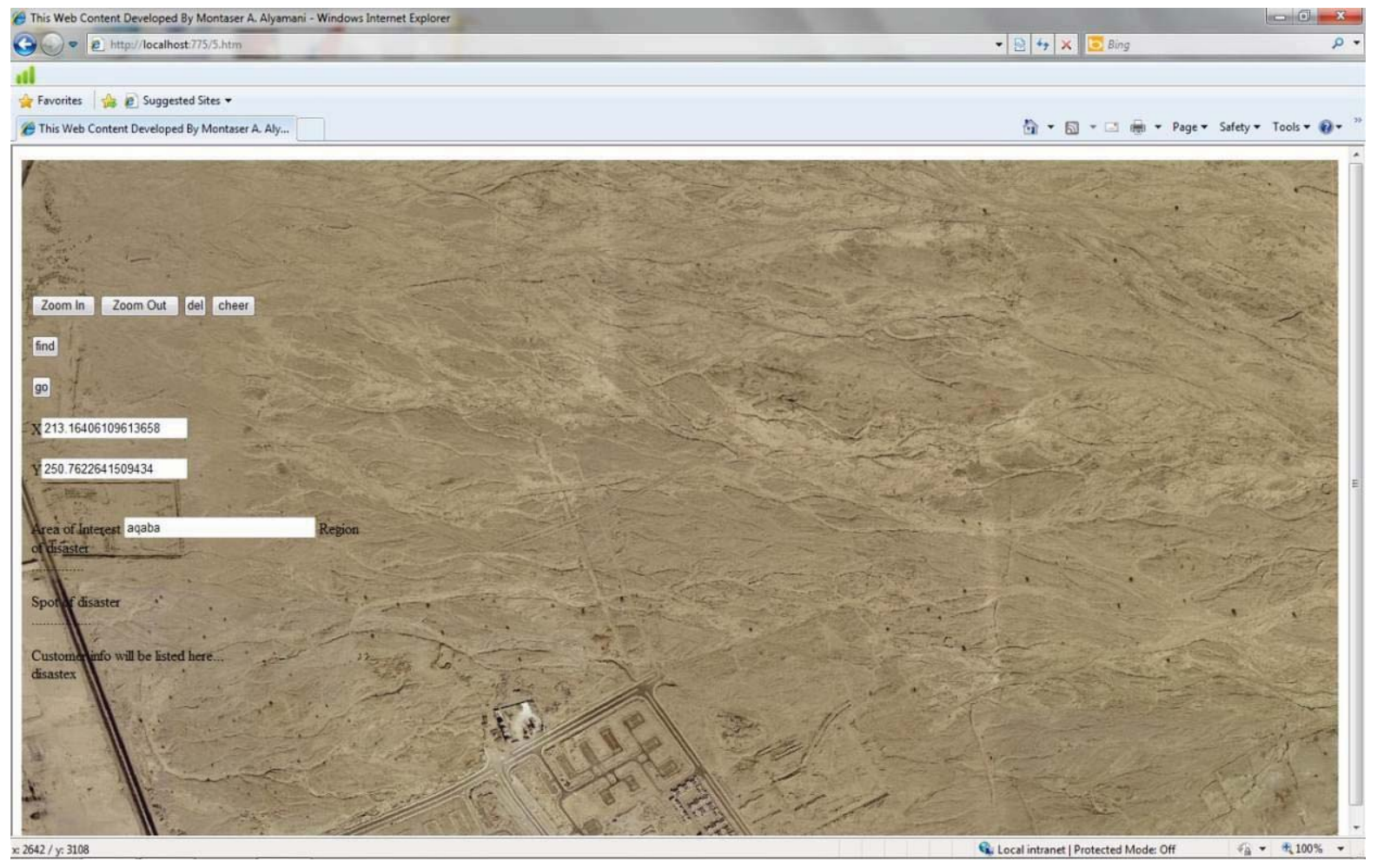

Fig.5 Disaster Area Coverage Shown By Dynamic Javascript Map

\subsection{Disaster Data Processing and Analysis}

There are many industrial database to be used to hold the final data, processed data (information), and final statistics as well for the ultimate new model. In this paper MS Access relational database has been chosen and used to implement the smart interactive dynamic disasters map, automating the analysis and processing data since Visual Basic coding is supported within it. However the JavaScript disaster mapping application developed and advanced in this paper had been tested with different vendors and types of databases such as : Oracle 11g, MySq1, Postgre, XML sheets, and flat text files successfully with high flexibility and efficiency.

The processing code should handle the routed treated data from the GSM 


\section{Mll Macrothink}

Business and Economic Research ISSN 2162-4860 2014, Vol. 4, No. 2

network server as follow:

- Find out subscribers count before and after disaster occurrence detecting the ratio of each sum of: live mobiles, turned off mobiles, out of coverage mobiles to setup criteria of rescuing priorities and disaster administering, then assign different color to each disaster level on the dynamic map for each relevant monitored area with its dimension and set up rescue priorities.

- Automating the process for specifying the relevant DCM Shared Medical Profile (DSMP) for each subscriber identity and restructure the medical drugs list of rescuing medical kit to be supplied to rescue crew.

- Using a special receiver (Reader) that detect the frequency of RFID and has a connection of Biometric Signature Identifier (BSI) databank to remote DCM room to find out the location of the missed mobile that may be not much distant from the victim or injured and identifying the missed.

3.3.1 Disaster Level Identification and Spots Locating

Design database table with the following data supplied of:

- Data of GSM cells of different GSM network vendors

- GSM cell location $(\mathrm{x}, \mathrm{y})$ or coordinates.

- Radiation pattern (Antenna double beam angles relevant to Cartesian Plane.

- Distance of coverage area.

Table that will be holding the these data named Dis8Cells designed with and the table that will be holding disasters areas with their level is Dis_Spots using Ms Access 2007 as database platform as shown in figure 7.

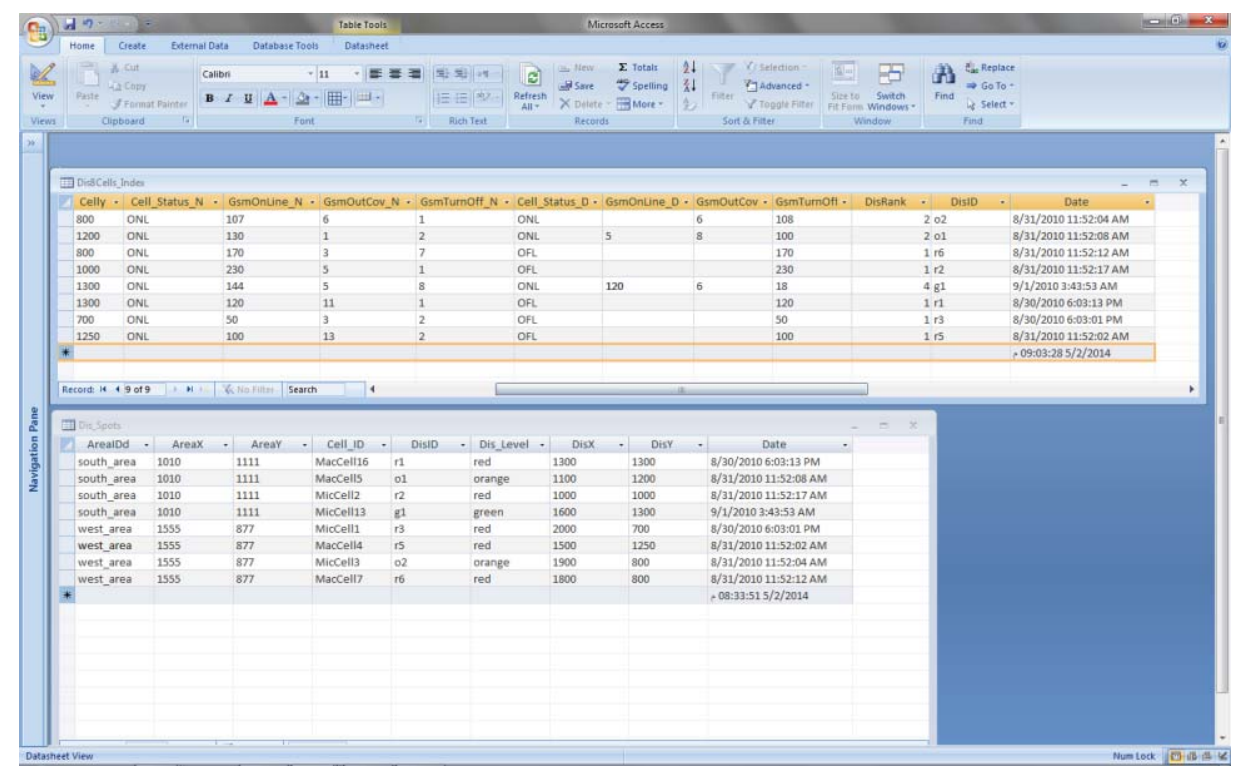

Fig.6 Ms Access Table Containing Disaster Locations and Analyzed Relevant Levels 


\section{Macrothink}

Business and Economic Research

ISSN 2162-4860

2014, Vol. 4, No. 2

By setting criteria to define disaster level and each color to be assigned for this may differ from one DCM policy decision maker to another according to many considerations like ; victim ages, victim medical condition, areas of disaster, legislation code, etc.

\subsubsection{Data Analysis Methodology (Developed Code )}

In this proposal four levels of disasters would be assumed as follow:

1) Green with symbol (g) as fair.

2) Yellow with symbol (y) as serious.

3) Orange with symbol (o) as critical.

4) Red with symbol (r) as severe.

The following columns in database with their relevant meaning as follow:

Cell_Status_N : ( GSM cell before disaster)

Cell_Status_D : ( GSM cell after disaster )

GsmOnLine_N : (number of mobiles online within the cell area before disaster)

GsmOnLine_D : (number of mobiles online within the cell area after disaster)

GsmOutCov_N : (number of mobiles out of reach within the cell area befor disaster)

GsmOutCov_D : (number of mobiles out of reach within the cell area after disaster)

GsmTurnOff_N : (number of mobiles turned off within the cell area before disaster)

GsmTurnOff_D : (number of mobiles turned off within the cell area after disaster)

ONL : online

OFL : offline

The criteria set as identified and programmed using visual Basic for application within Ms Access 2007.

Presenting the final data as disasters colored area showing the disaster coverage with coordinates for each disaster spot and level as shown in 


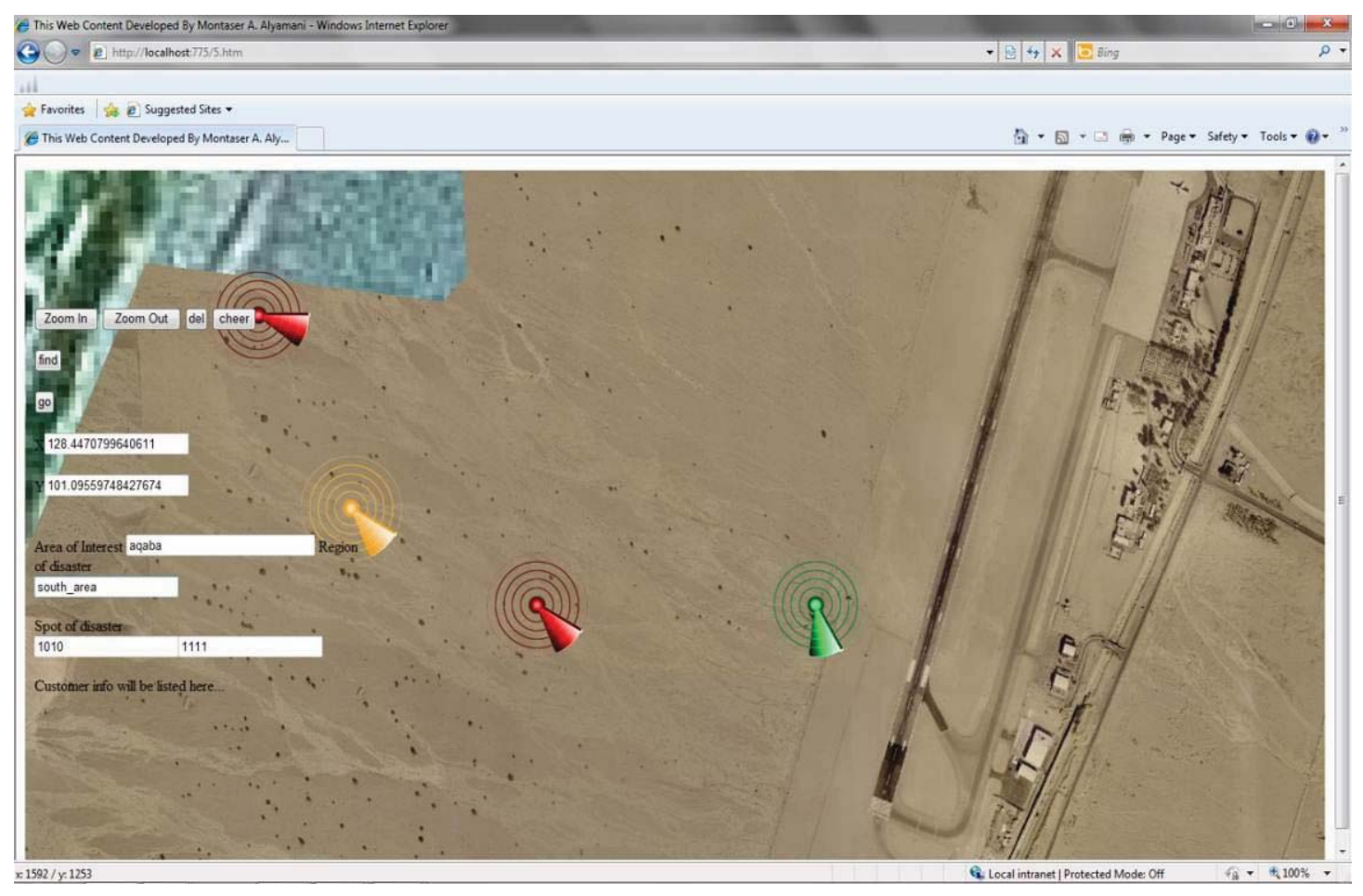

Fig.7 Disaster Areas WithTheir Levels Shown On the Dynamic Map

\subsubsection{Recue Data Management}

By comparing the pre transmitted thumb for each person before disaster occurrence with the ready saved thumb databank collection finding the relevant DCM Shared Medical Profile DSMP according to their discriminated National ID

(as assigned Person_ID in database table PreResc )so access the medical briefing profile ( as in table Med_Profile ) to find out the most valuable medication to extract and integrate it into final medication table ( as in table DisMed ). Also the rescue table will integrate the most of table Med_Profile to perform the rescue mission in the field whether pre stored database on E-Pad or any such device or online using any portable RF communication service available. The reference database table that holds Biometric Signature Identifier (BSI) is BsiSmp which holds both Person ID as a (National ID and the relevant BSI saved as a Package since it is an image ( binary ) object . Figure 9 shows the tables used for medical and rescue data administering. No software snippet code supplied since establishing the concept and data processing more important than software automating methodology while this scenario is more applicable in realistic world, however database was proposed In prior since no such access for people identities and data such as medical profile besides automating software can be deployed easily once data resources are available. 


\section{MlMacrothink}

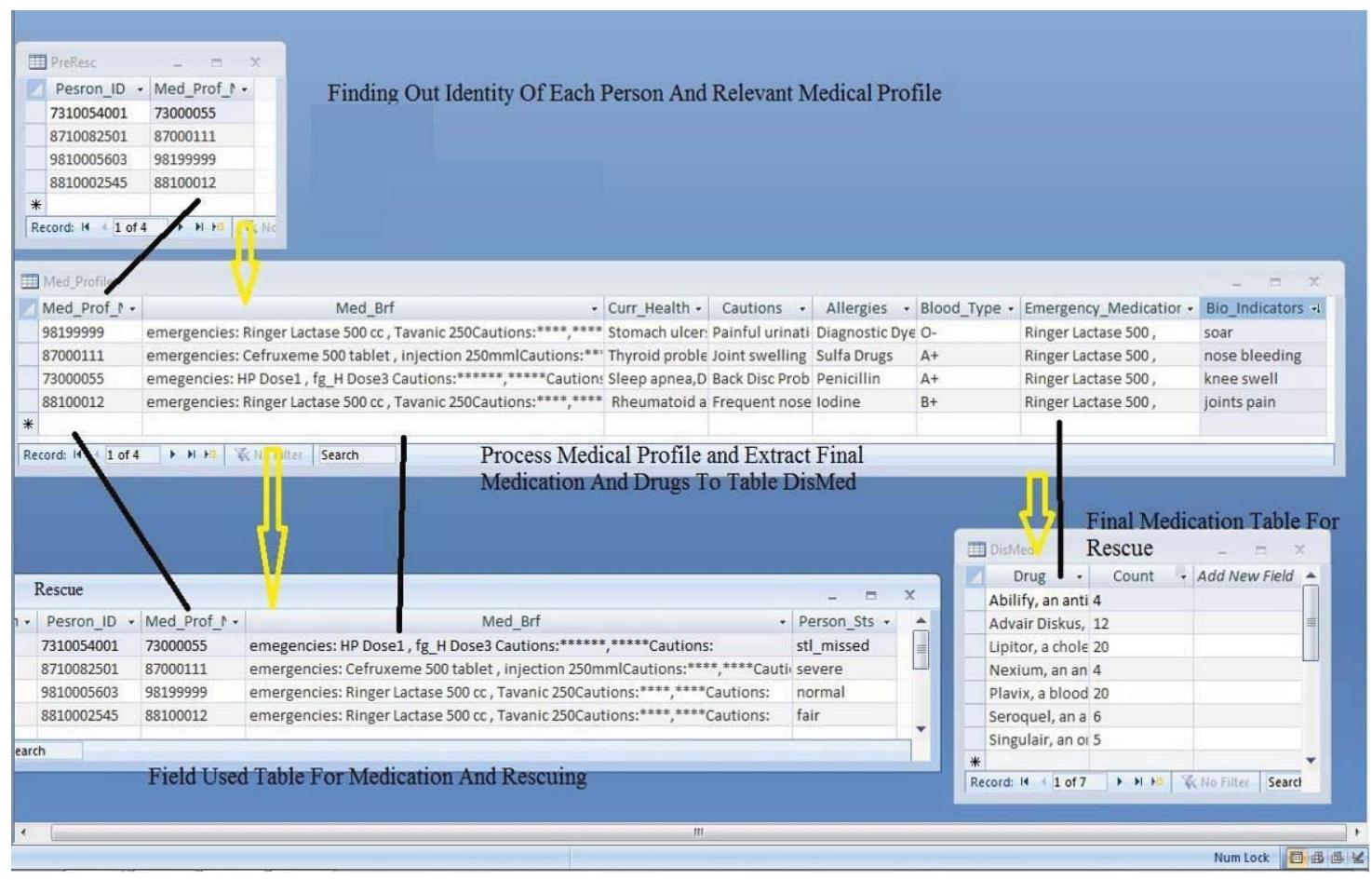

Fig. 8 Ms Access Tables Used For Medical And Rescue Data Administering

\subsubsection{RFID What, How Concept}

Radio-frequency identification (RFID)

Radio frequency (RF) technology is used in many different applications, such as television, radio, cellular phones, radar, and automatic identification systems. RFID stands for radio frequency identification and describes the use of radio frequency signals to provide automatic identification (1) Unlike the electronic article surveillance (EAS) systems used for theft detection, RFID provides a unique serial number for identification of an object (2). RFID is used in the Mobil Speed pass system to pay for gas without going into the store, in automobile immobilizer systems to prevent theft by uniquely identifying a key with an embedded chip, in Fast Lane and E-Z Pass toll road systems to automatically pay tolls without stopping, in animal identification, in secure entry cards to secure access to buildings, and in the supply chain to manage the flow of pallets, cases, and items (2). RFID technology was invented in 1948, but it was not commercialized until the 1980s. One of its first known applications was during World War II, when it was used by the British radar system to differentiate between friendly and enemy aircraft with attached radio transponders (3).

An RFID system consists of tags, readers, communication protocols, computer networks, and databases. A typical RFID system being standardized by EPCglobal is shown in Figure. 9

(1) Intermec Technologies Corporation, "RFID overview". Available:

http://epsfiles.intermec.com/eps_files/eps_wp/IntroRFID_wp_web.pdf 


\section{MInstitute Macrothink $_{\text {Int }}$}

Business and Economic Research

ISSN 2162-4860

(2) S. Garfinkel and B. Rosenberg, Eds., RFID: Applications, Security, and Privacy, Upper Saddle River, New Jersey: Addison-Wesley, 2006.

(3) T. Mital, "The emergence of RFID," M.S. project, BAUER College of Business, University of Houston, Houston, Texas, 2003. Available: http://www.uhisrc.com/ FTB/RFID/RFID\%20Sep03.pdf

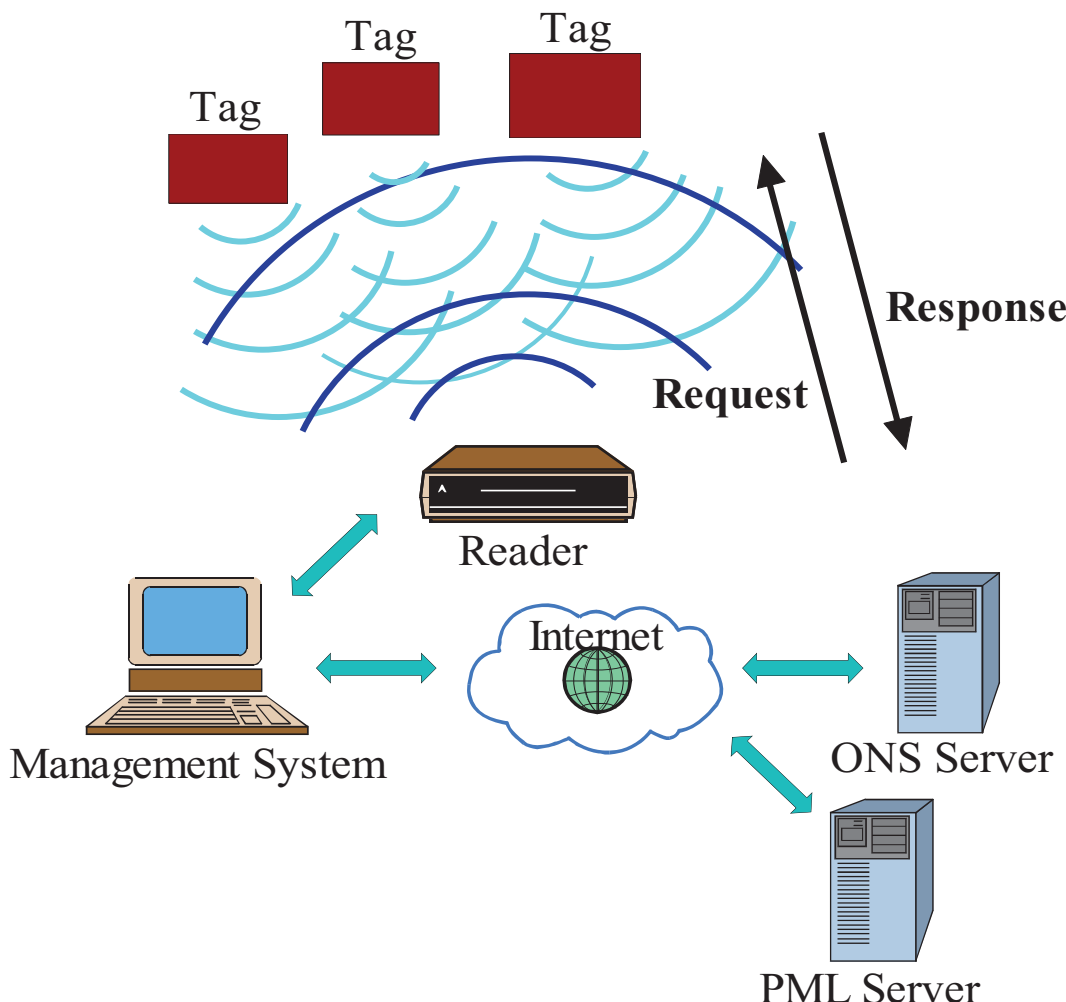

Fig.9 RFID system

\section{Readers}

A reader, also known as an interrogator, is a device used to query one or more tags within its range and communicate with them. It consists of one or more antennas that emit radio waves and receive signals from one or more tags. The reader sends a request as an interrogating signal for identification information to the tag. The tag wakes up and responds or broadcasts with the respective information by sending an encoded modified signal, which the reader decodes, forwarding it to the data processing device ${ }^{1}$

\section{Frequencies2}

1 Richardson-Electronics, "RFID". Available:

http://www.ferret.com.au/Showcases/Richardson-Electronics/114211

Webopedia, “RFID”. Available: http://www.webopedia.com

${ }^{2}$ Sen, Dipankar; Sen, Prosenjit; Das, Anand M. (2009), RFID For Energy and Utility Industries, PennWell, ISBN 978-1-59370-105-5, pp. 1-48 


\section{Al Macrothink}

Business and Economic Research

ISSN 2162-4860

2014, Vol. 4, No. 2

The selected frequency service to be selected for RFID service is $433 \mathrm{MHZ}$ and marked by yellow paint in the table

RFID frequency bands

\begin{tabular}{|c|c|c|c|c|c|}
\hline Band & Regulations & Range & Data speed & Remarks & $\begin{array}{l}\text { Approximate tag cost } \\
\text { in volume (2006) US } \$\end{array}$ \\
\hline $120-150$ kHz (LF) & Unregulated & $10 \mathrm{~cm}$ & Low & $\begin{array}{l}\text { Animal identification, } \\
\text { factory data collection }\end{array}$ & $\$ 1$ \\
\hline $13.56 \mathrm{MHz}$ (HF) & $\underline{\text { ISM }}$ & $\begin{array}{l}10 \mathrm{~cm} \mathrm{-} \\
1 \mathrm{~m}\end{array}$ & $\begin{array}{l}\text { Low to } \\
\text { moderate }\end{array}$ & $\begin{array}{l}\text { Smart } \\
(\underline{\text { MIFARE}}, \underline{\text { ISO/IEC }} \\
\underline{\underline{14443}})\end{array}$ & $\$ 0.50$ \\
\hline $433 \mathrm{MHz}$ (UHF) & $\begin{array}{ll}\text { Short } & \text { Range } \\
\text { Devices } & \end{array}$ & $\begin{array}{l}1-100 \\
m\end{array}$ & Moderate & $\begin{array}{l}\text { Defence applications, with } \\
\text { active tags }\end{array}$ & $\$ 5$ \\
\hline $\begin{array}{l}865-868 \mathrm{MHz} \\
\text { (Europe) } \\
902-928 \mathrm{MHz} \text { (North } \\
\text { America) UHF }\end{array}$ & ISM band & $1-12 \mathrm{~m}$ & $\begin{array}{l}\text { Moderate } \\
\text { to high }\end{array}$ & EAN, various standards & $\$ 0.15$ (passive tags) \\
\hline $\begin{array}{l}2450-5800 \mathrm{MHz} \\
\text { (microwave) }\end{array}$ & ISM band & $1-2 \mathrm{~m}$ & High & $\begin{array}{l}802.11 \text { WLAN, Bluetooth } \\
\text { standards }\end{array}$ & $\$ 25$ (active tags) \\
\hline $\begin{array}{l}3.1-10 \mathrm{GHz} \\
\text { (microwave) }\end{array}$ & Ultra wide band & $\begin{array}{ll}\text { to } & 200 \\
\mathrm{~m} & \end{array}$ & High & $\begin{array}{l}\text { requires semi-active or } \\
\text { active tags }\end{array}$ & $\$ 5$ projected \\
\hline
\end{tabular}

\section{Results}

The results of combination Javascript with GSM mobile service with different level of data collection, and automation by proposing new concepts, services, and model will create a high dynamic disaster management tool which in turn results in deploying solution over different operating systems ( cross platform ) and cross browsers. Besides that anticipating the most damaged area by identifying and defining different set of criteria for analyzing the coverage area for human activities and resources

\subsection{Results Discussion}

The development of such conceptual solution will play major role especially for those creating startup units and institute for disaster and crisis management. Coding is straight forward; new added tracking technology such as RFID will facilitate the procedure of search on missed people and identifying them so decrease the count of the missed victims. Beside that using the new concept of DSMP will accelerate the time medical kit preparing by pre identifying the most needed medical resources to accommodate medication process in the disaster field increasing the chances of injured victims to be healed and cured with less harms. 


\section{Mll Macrothink}

Business and Economic Research

ISSN 2162-4860

2014, Vol. 4, No. 2

\section{Conclusion and Recommendations}

Designing a dynamic smart mapping for disaster management tool will enhance the disaster management system of data grabbing, analysis, and automating will decrease the humanitarian damage for victims both the missed and the injured by decreasing the time duration of response adding high level of pre preparedness for rescue team (medical and relief).

\subsection{Conclusion}

*Using JavaScript and Global System For Mobiling ( GSM) service aided solution results in increasing productivities, cut off cost of running such a system in Disaster and Crisis Management System (DCMS) and Disaster Management Tool( DMT).

*JavaScript mapping and processing code for defining disaster' attributes simplicity in developing and maintaining.

*Decreasing the mass of disaster damage.

* System could be modified based on requirements and any additional information.

* GIS mapping tool can be modified to serve in different level of disasters and crises.

*Radio Frequency Identifier (RFID), Biometric Signature Identifier (BSI), and DCM Shared Medical Profile (DSMP) could be integrate into higher disaster services easily without high expenses for development and automation process.

*Dynamic map can integrate and manipulate different vendor's databases easily without additional complex setup since using Ajax method for each separate service.

\subsection{Recommendations and Future Work}

- Integrating Radio Frequency Identifier (RFID) as an effective tool with Global System For Mobiling( GSM) mobiles need to be approve and there should be a new standardization for industrial mobile service integration.

- New legislation should be made to consider aspects of tracking people and identifying identities by the new proposed services and tool of Biometric Signature Identifier ( BSI) and DCM Shared Medical Profile(DSMP ) overlapping with Disaster and Crisis Management System (DCMS) administering.

- Practical approach for JavaScript interactive map would give better results if Global System For Mobiling (GSM) cells data grabbed by connecting map to online Global System For Mobiling (GSM) data servers.

- An easy and effective alternative choice for GIS and disaster management tool compared to expensive software available in the market which can be connected with ease to any type of databases ( Oracle, Ms SQL, IBM DB2, Ms Access, Ingres, etc) and can deal with data locally or in intranet environment thus preventing the misuse of the data and give users high degree of safety, privacy, and reliability data manipulation.

- The JavaScript mapping system Works with all operational environments for PCs 


\section{MInstitute Macrothink}

Business and Economic Research ISSN 2162-4860 2014, Vol. 4, No. 2

( Microsoft Windows, Linux, Novell, Unix, etc. ) whether as a desktop application or as web application with high flexibility to connect it to remote sensors and data-logger easily.

- The proposed developed application can be programmed and developed easily

- without extra cost saving time and effort besides its ability to deal with high resolution satellite raster ( images ) as well as aerial photographs providing that coordinates of location can be customized and shown in different international projections (UTM, JTM, Lon / Lat , etc) immediately and locally ( offline ) without internet connection.

- Can be used to track people easily with live ( online ) tracking device installed in vehicle or man plus that the application is small in size, and does not require installation on the hosting computer.

\section{References}

Alexander, David. (1991). "Natural disasters: a framework for research and teaching." Disasters 15, 209-26. http://dx.doi.org/10.1111/j.1467-7717.1991.tb00455.x

Alexander, David. (1991). Natural disasters: a framework for research and teaching. Disasters 15, 209-26. http://dx.doi.org/10.1111/j.1467-7717.1991.tb00455.x

Guha-Sapir, D., Hargitt, \& Hoyois, P, (2004) Thirty Years of Natural Disasters 1974-2003: The Numbers. Presses Universitaires de Louvain

Intermec Technologies Corporation, "RFID overview". Available: http://epsfiles.intermec.com/eps_files/eps_wp/IntroRFID_wp_web.pdf

Mileti, D. S., Darlington, J. D., Passaini, E., Forest, B. C., \& Myers, M. F. (1995). Toward an integration of natural hazards and sustainability, Environmental Professional, 17, 117-26

Richardson-Electronics,

"RFID".

Available:

http://www.ferret.com.au/Showcases/Richardson-Electronics/114211

Rodríguez, J., Vos, F., Below, R., \& Guha-Sapir, D. (2009). Annual Disaster Statistical Review 2008: The numbers and Trends. The Centre for Research on the Epidemiology of Disasters.

S. Garfinkel \& B. Rosenberg, Eds., RFID: Applications, Security, and Privacy, Upper Saddle River, New Jersey: Addison-Wesley, 2006.

Sen, Dipankar; Sen, Prosenjit; Das, Anand M. (2009). RFID For Energy and Utility Industries, PennWell, ISBN 978-1-59370-105-5, pp.1-48

Shaluf, I. M. (2008) Technological disaster stages and Management. Disaster Prevention and Management. 17(1), 114-126. http://dx.doi.org/10.1111/j.1467-7717.1991.tb00455.x

T. Mital, "The emergence of RFID," M.S. project, BAUER College of Business, University of Houston, Houston, Texas, 2003. Available: http://www.uhisrc.com/ FTB/RFID/RFID\%20Sep03.pdf

UNHCR. (2007) UNHCR's response to the Tsunami emergency in Indonesia and Sri Lanka, 


\section{MInstitute Macrothink}

Business and Economic Research ISSN 2162-4860 2014, Vol. 4, No. 2

December 2004 - November 2006. An independent evaluation by Bobby Lambert 2007

UNISDR. (2009) UNISDR Terminology on Disaster Risk Reduction

Webopedia, "RFID”. Available: http://www.webopedia.com

\begin{tabular}{|c|}
\hline Nomenclatures \\
\hline BAP : Battery-Assisted Passive \\
\hline BSI: Biometric Signature Identifier. \\
\hline DC Power : Direct Current Power \\
\hline DAC: Disaster And Crisis \\
\hline DCM: Disaster and Crisis Management. \\
\hline DCMS: Disaster and Crisis Management System. \\
\hline DMT: Disaster Management Tool. \\
\hline DSMP: DCM Shared Medical Profile. \\
\hline GIS: Geographic Information System \\
\hline GPR; General Purpose Register \\
\hline GPS: Global Positioning Service ( System ) \\
\hline GSM ; GLOBAL SYSTEM FOR MOBILING. \\
\hline MIS: Management Information System \\
\hline Ms Access 2007 : Relational Database from Microsoft \\
\hline OEM: Original Electronic Manufacturer \\
\hline OOP: Object Oriented Language \\
\hline PRAT : Passive Reader Active Tag \\
\hline RF: Radio Frequency is a rate of oscillation in the range of around $3 \mathrm{kHz}$ to $300 \mathrm{GHz}$ \\
\hline Visual Basic : A Third-Generation Event-Driven Programming Language From Microsoft \\
\hline
\end{tabular}

\section{Appendix}

Code developed and provided by Eng. Montaser

Alyamani accompanied by CD-Rom

Snippet JavaScript code to simulate and automate X-Y calculation using trigonometric model 


\section{Al Macrothink}

Business and Economic Research

ISSN 2162-4860

2014, Vol. 4, No. 2

function get_shape ()\{

var facx;

var facy;

var xn;

var yn;

var xnn;

var ynn;

var tol;

var tot;

var tolx;

var toty;

var zza;

var zzaa;

var zzb;

var idx;

var idy;

var colordis;

var colort;

var ddxn;

var ddyn;

var objCounter2 $=1$;

var loctimv;

var stopxn $=1$;

var stopyn $=1$;

var areaid $=$ document.parcels.finder.value;

var area $\_$loc $=$getid(areaid);

var tro = getid('img1');

tol $=$ tro.offsetLeft ;

tot $=$ tro.offsetTop;

var aa;

var bb;

$\operatorname{var} \mathrm{p}=0$;

If $(0=<(a a$ and $b b)=<180)\{$

if $((180-a)=<(180-b))\{$

for $(\mathrm{aa}=1 ; \mathrm{aa}<$ angle.length $; \mathrm{aa}+=1)\{$

if (null $==$ area loc) $\{$ alert('Non of areas or coordinates been supplied') $\}$

else \{

var coords = area_loc.coords.split(","); 


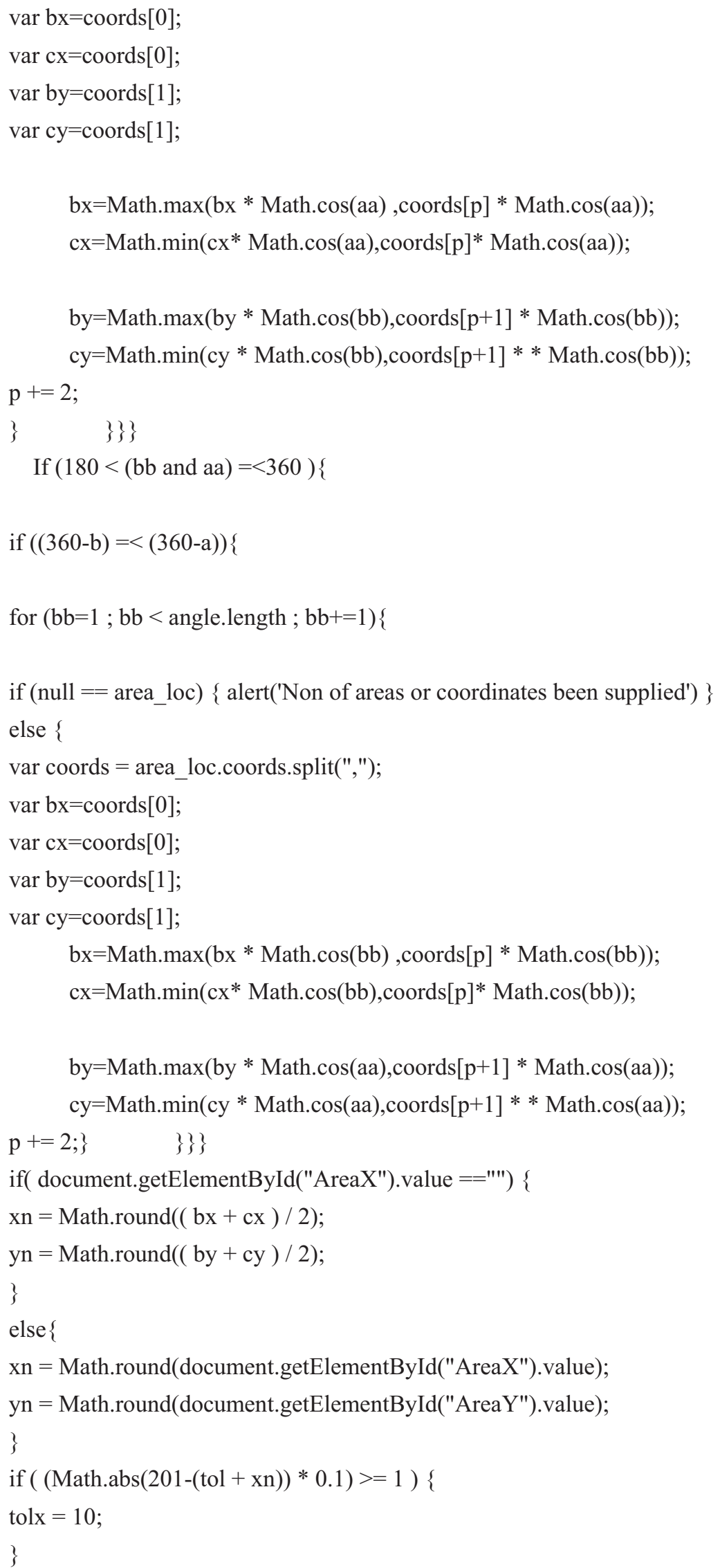




\section{Al Macrothink}

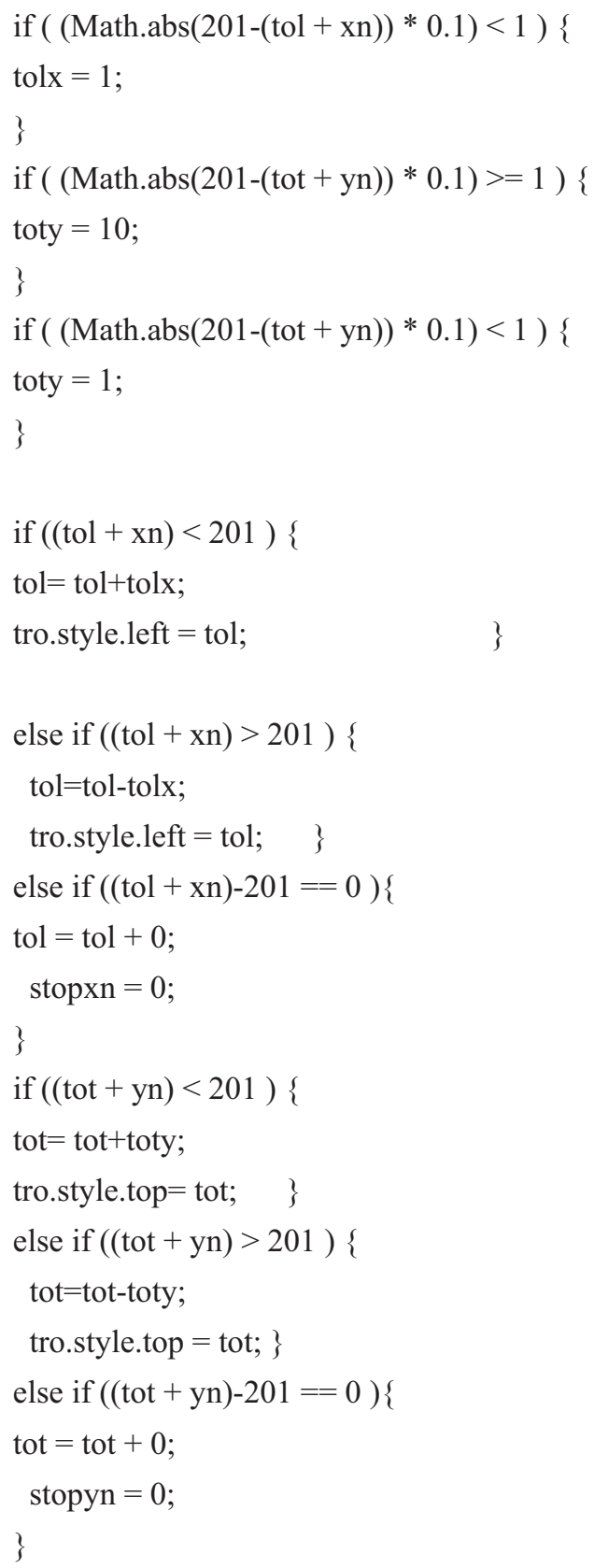

Snippet Javascript code to identify and show disaster locations with their relevant coordinates and levels for all disaster spots

loctimv $=$ window.setTimeout('get_shape ()$; ', 1)$;

if $($ stopxn $==0 \& \&$ stopyn $==0)\{$

clearTimeout(loctimv);

var mediago = areaid.concat(".wav");

document.getElementById("soundeffect").src= mediago;

zza $=$ document.getElementsByName('dan');

zzaa $=$ (zza.length) / 3;

if(document.getElementById('rad') != null) \{

var mm; 
for $(\mathrm{mm}=0 ; \mathrm{mm}<\mathrm{zzaa} ; \mathrm{mm}++)\{$

delobjrad('rad'); \} \}

for $(z z b=0 ; z z b<$ zzaa; $z z b++)\{$

$\mathrm{idx}=$ "DisX";

idy = "DisY";

colordis = 'colour';

var $\mathrm{idxx}=\mathrm{idx}$.concat(objCounter2);

var idyy = idy.concat (objCounter2);

var colrrr $=$ colordis. $\operatorname{concat}($ objCounter 2$)$;

$\mathrm{ddxn}=$ Math.round(document.getElementById(idxx).value);

ddyn = Math.round(document.getElementById(idyy).value);

colort $=($ document.getElementById(colrrr).value $)$. concat $("$.gif");

objCounter2++;

var imgTak = document.createElement("img");

var imgTagk = document.getElementById('img1');

imgTak.name = "imgv1";

if $($ colort =="orange .gif" $)\{$ imgTak.src = "orange.gif"; $\}$

if $($ colort $=="$ red.$g i f ")$ imgTak.src = "red.gif"; $\}$

if $($ colort =="green .gif" $)$ imgTak.src = "green.gif"; $\}$

imgTak.id = "rad";

imgTak.setAttribute("align","center");

imgTak.style.zIndex = "3000";

imgTak.style.margin = "0px auto";

imgTak.style.top = ddyn+imgTagk.offsetTop+"px";

imgTak.style.left = ddxn+imgTagk.offsetLeft+"px";

imgTak.style.position = "absolute";

imgTak.style.width = 120+"px";

imgTak.style.height = 120+"px";

imgTak.className ="dynamicDiv";

document.getElementById('myDiv').appendChild(imgTak); $\}$ \} \}

\}// end of function;

Snippet VBA code to analyze and identify the level of disaster according to the relevant attributes and resources

Dim mydb As DAO.Database

Dim MyRs As DAO.Recordset

Set mydb $=$ CurrentDb 'CurrentDb ()

Set MyRs = CurrentDb.OpenRecordset("Dis8Cells", dbOpenDynaset)

Dim DisID As String

Dim n As Integer

$\mathrm{n}=0$ 
Do Until MyRs.EOF

If (MyRs![Cell_Status_D] = "ONL" And (MyRs![GsmOutCov_D] + MyRs![GsmTurnOff_D]) <

$(1 / 3) *($ MyRs! [GsmOnLine_D] $))$ Then

DisID $=\mathrm{g}+\mathrm{n}$

End If

If (MyRs![Cell_Status_D] = "ONL" And (MyRs![GsmOutCov_D] + MyRs![GsmTurnOff_D]) > $(1 / 3) *($ MyRs![GsmOnLine_D]) And (MyRs![GsmOutCov_D] + MyRs![GsmTurnOff_D] $)<(2$

/3) * (MyRs![GsmOnLine_D])) Then

$\operatorname{DisID}=\mathrm{y}+\mathrm{n}$

End If

If (MyRs![Cell_Status_D] = "ONL" And (MyRs![GsmTurnOff_D]) >=

(MyRs![GsmOnLine_D])) Then

DisID $=\mathrm{o}+\mathrm{n}$

End If

If (MyRs![Cell_Status_D] = "OFL") Then

DisID $=r+n$

End If

MyRs.MoveNext

Loop

MyRs.Close

Set MyRs $=$ Nothing

$\mathrm{n}=0$

\section{Copyright Disclaimer}

Copyright for this article is retained by the author(s), with first publication rights granted to the journal.

This is an open-access article distributed under the terms and conditions of the Creative Commons Attribution license (http://creativecommons.org/licenses/by/3.0/). 